\title{
Pediatrik Üreteropelvik Bileşke Darlığı Yönetiminde Tek Merkez Deneyimi
}

\author{
Single Center Experience in Pediatric Ureteropelvic Junction Obstruction Management
}

${ }^{1}$ Tülay Becerir, ${ }^{1}$ İlknur Girişgen, ${ }^{2}$ Hande Şenol, ${ }^{3}$ Olga Yaylalı, ${ }^{4}$ Osman Uzunlu, ${ }^{1}$ Selçuk Yüksel

${ }^{1}$ Pamukkale Üniversitesi Tip Fakültesi Çocuk Nefroloji Bilim Dalı, Denizli, Türkiye

${ }^{2}$ Pamukkale Üniversitesi Tip Fakültesi Biyoistatistik Anabilim Dalı, Denizli, Türkiye

${ }^{3}$ Pamukkale Üniversitesi Tip Fakültesi Nükleer Tip Anabilim Dalı, Denizli,

Türkiye

${ }^{4}$ Pamukkale Üniversitesi Tip Fakültesi Çocuk Cerrahisi Anabilim Dalı, Denizli, Türkiye
Correspondence:

Tülay BECERİR

Pamukkale Üniversitesi Tip Fakültesi Çocuk Nefroloji Bilim Dalı, Denizli, Türkiye

e-mail: tlyince@hotmail.com

\section{Özet}

Üreteropelvik bileşke darlığı (UPD), tanısı ile izlenen çocuk hastaların yönetimi tartışmalıdır ve merkezlere göre değişkenlik gösterir. Bu çalışmada Pamukkale Üniversitesi Çocuk Nefroloji Kliniğinde UPD tanısıyla takip edilen hastaların başvuru ve izlem bulgularının değerlendirilmesi amaçlanmıştır. Pamukkale Üniversitesi Çocuk Nefroloji kliniğinde Ocak 2014 ile Ağustos 2021 tarihleri arasında UPD tanısı ile izlenen çocuk hastaların verileri retrospektif olarak değerlendirildi. Hastaların demografik ve klinik özellikleri, başvuruda, izlemde birinci yılda ve son kontrolde çekilen üriner sistem USG bulguları ve başvuruda ve birinci yılda çekilen Mercaptoacetyltriglycine (MAG3) sintigrafi bulguları incelendi. Hastaların 31’i (\%70.5) erkek, 13’ü (\%29.5) kızdı. Hastaların ortalama takip süresi $47.4 \pm 31.1$ (24-120 ay) ay olarak saptandı. Hastaların 18'inde (\% $\left.{ }^{4} 41\right)$ UPD'e eşlik eden böbrek anomalisi mevcuttu. On dokuz hastaya piyeloplasti operasyonu uygulandı. Piyeloplasti uygulanan hastaların ilk başvuru USG bulguları ile 1. yıl USG bulguları değerlendirildiğinde parankimde incelme, pelvis ön-arka çapı genişliği bulgularında düzelme olduğu saptandı. Piyeloplasti yapılmayan hastalar arasında 3 hastanın USG bulgularının kötüleştiği görüldü. Veriler tekrar incelendiğinde bu üç hastanın operasyonu kabul etmeyen ailelerin çocukları olduğu saptandı. Piyelopilasti yapılan ve yapılmayan hastaların, ilk başvuru ve izlemde birinci yılda çekilen MAG-3 sintigrafisi bulguları arasında belirgin değişiklik yoktu. Bu çalışmada hem cerrahi hemde konservatif yaklaşım ile izlenen hastaların USG ve MAG3 sintigrafisi bulgularının stabil kaldığı veya iyileștiği saptanmıştır Bu hasta grubunda USG ve MAG3 sintigrafisi sonuçlarının birlikte yorumlanması önemlidir. Özelikle konservatif yaklaşıma karar vermede ailelerin takip planlarına uyum sağlayıp sağlayamayacakları da göz önüne alınmalıdır.

Anahtar Kelimeler: üreteropelvik darlık, çocuk, hidronefroz

\section{Abstract}

Management of pediatric patients with the diagnosis of ureteropelvic junction obstruction (UPO) is controversial and varies according to centers. In this study, it was aimed to evaluate the admission and follow-up findings of the patients followed up with the diagnosis of UPO in Pamukkale University Pediatric Nephrology Clinic. The data of pediatric patients who were followed-up with the diagnosis of UPO in Pamukkale University Pediatric Nephrology Clinic between January 2014 and August 2021 were evaluated retrospectively. Demographic and clinical characteristics of the patients, urinary system USG findings at admission, at the first year of follow-up, and at the last follow-up, and Mercaptoacetyltriglycine (MAG3) scintigraphy findings at admission and at the first-year follow-up were analyzed. Thirty-one $(70.5 \%)$ of the patients were male and $13(29.5 \%)$ were female. The mean follow-up period of the patients was $47.4 \pm 31.1$ (24-120 months) months. Eighteen of the patients ( $\left.{ }^{4} 41 \%\right)$ had renal anomaly accompanying UPO. Nineteen patients underwent pyeloplasty operation. First admission USG findings and 1st year USG findings of patients who underwent pyeloplasty were evaluated. It was determined that there was an improvement in the findings of thinning of the parenchyma and the width of the anterior-posterior diameter of the pelvis. Among the patients who did not undergo pyeloplasty, the USG findings of 3 patients deteriorated. When the data were re-examined, it was determined that these three patients were children of families who did not accept the operation. There was no significant difference between the MAG-3 scintigraphy findings at the first admission and the first year in the patients who underwent pyelopiplasty and those who did not In this study, it was determined that the USG and MAG3 scintigraphy findings of the patients followed up with both surgical and conservative approaches remained stable or improved. It is important to evaluate USG and MAG3 scintigraphy results together in the management of this patient group. In particular, it should be taken into account whether families can adapt to follow-up plans when deciding on the conservative approach.

Keywords: ureteropelvic stenosis, child, hydronephrosis 


\section{Giriş}

Üreteropelvik bileşke darlığı (UPD), renal pelvisten üretere idrar akımında azalmaya neden olan durumları ifade eder. UPD hidronefroza ve bazı hastalarda ise idrar yolu enfeksiyonuna ve/veya ürolitiyazise neden olur. Uygun tedavi edilmediğinde böbrek fonksiyonlarının progresif bozulması ile sonuçlanır (1). Sebepleri arasında üreterde adinamik segment, üreter içinde kapakçık veya polipler, aberran damar basısı, insersiyon anomalileri (üreterin pelvise yüksek giriş yapmas1), fibröz bantlar, böbrek mobilitesi, üriner sistem taşı, ameliyat sonrası/inflamatuar/iskemik darlık ve malignite gibi patolojiler siralanabilir $(1,2)$. UPD çocuklarda çoğunlukla konjenital olarak gelişir. Günümüzde prenatal ultrasonografi (USG) tetkikinin yaygınlaşması ile UPD'si olan hastalar en çok antenatal hidronefroz bulgusu ile başvurmaktadır (3). UPD'li olgularda tam obstrüksiyonun varlığ 1 cerrahi tedavi gerektirir. $\mathrm{Bu}$ nedenle UPD varlığında şiddetini belirlemek gerekir. Günümüzde UPD' nin şiddetini belirlemede USG de saptanan hidronefroz (pelvikalikseal dilatasyonun) düzeyi ve Technetium-99m Mercaptoacetyltriglycine (MAG3) sintigrafisi ile saptanan renal fonksiyonlar kullanılmaktadır $(1,5)$. Literatürde USG ile yapılan hidronefroz değerlendirmesinde çeşitli sinıflandırma sistemleri kullanılmaktadır. Society of Fetal Urology (SFU), urinary tract dilation (UTD) ve Önen evrelemeleri bu yöntemler arasında en sık kullanılanlardır $(1,6,7)$. Ancak bu yaklaşımların hiç biri bu hasta gruplarının değerlendirmesi için altın standart yöntemler değildir. Bu yöntemler ile doğru saptanamayan UPD ciddiyeti cerrahide gecikmeye neden olarak kalıcı böbrek hasarına veya bazı olgularda gereksiz cerrahi girişim yapılmasına neden olabilmektedir $(5,8,9)$.

Genelde UPD hastalarının cerrahi tedavisi veya konservatif yöntemle izlemi ile ilgili uzun dönem veriler kısitlı ya da merkezlere göre değișkendir. Tedavide güncel eğilim konservatif tedavi lehine kaymakla birlikte mevcut veriler bu yaklaşımı desteklemekte yetersiz kalmaktadır (5). Bu çalışmada Pamukkale Üniversitesi Çocuk Nefroloji Kliniğinde UPD tanısı ile tedavi edilen hastaların başvuru ve izlem bulgularının değerlendirilmesi amaçlanmıştır.

\section{Materyal Metod}

Pamukkale Üniversitesi Çocuk Nefroloji kliniğinde Ocak 2014 ile Ağustos 2021 tarihleri arasında UPD tanısı ile izlenen toplam 53 çocuk hastanın verileri retrospektif olarak değerlendirildi. En az 2 y1l süre ile kliniğimizde takipleri yapılan, izlemde en az 1 y1l ara ile 2 veya daha fazla üriner sistem USG ve MAG3 sintigrafisi çekilmiş olan hastalar çalışmaya dahil edildi. Bu kriterlere göre toplam 44 hasta çalışmaya alındı. Dokuz hasta takip süresi 2 yıldan az, ek majör üriner sistem anomalileri ve izlemde 2' den az MAG-3 sintigrafisi ve/veya üriner sistem USG görüntülemesi olmas1 nedenleriyle çalışmaya dâhil edilmedi. Hastaların son kontroldeki yaşı başvuru anındaki yaşı, başvuru nedeni, izlem süresi, UPD' ye yönelik operasyon geçirip geçirmediği, opere oldu ise tanıdan ne kadar süre sonra opere olduğu, eşlik eden böbrek anomalisi (multikistik displastik böbrek (MKDB), veziko üreteral reflü (VUR), atnalı böbrek, çapraz ektopi, üreterovezikal darlık (UVD), soliter böbrek, çift toplayıcı sistem) varlığı, başvuruda, izlemde birinci yılda ve son kontrolde çekilen üriner sistem USG bulguları ve başvuruda ve birinci y1lda çekilen MAG-3 sintigrafi bulguları kayıt edildi. SFU, UTD ve Önen sınıflamalarına göre ayrı ayrı evrelemeleri yapild $1(6,7)$.

Çalışma için Pamukkale üniversitesi Tıp Fakültesi girişimsel olmayan çalışmalar etik kurulundan (23.09.2021-E.106852) onay alındi.

Hastaların verileri SPSS 21.0 programında değerlendirildi, ortalama/aralık değer ve yüzdelik dağılımlar hesaplandı. Ki kare testi ile değişkenlerin kıyaslaması yapıldı. p değerinin 0.05 'ten küçük olması istatistiksel olarak anlamlı kabul edildi.

\section{Sonuçlar}

Çalışmaya dahil edilen hastaların 31'i (\%70.5) erkek, 13'ü (\%29.5) kızdı. Hastaların ortalama takip süresi $47.4 \pm 31.1$ (24-120 ay) ay olarak saptandi. On dokuz hastaya piyeloplasti 
operasyonu uygulandi. Üç hastaya kabul etmediği için operasyon uygulanmadı piyeloplasti yapılması planlanmıştı ancak aile (Tablo 1).

Tablo1. Hastalara ait demografik veriler

\begin{tabular}{ll}
\hline Cinsiyet & $\mathrm{n}(\%)$ \\
Erkek & $31(70.5)$ \\
Kiz & $13(29.5)$ \\
\hline Başvuru yaşı & $\mathrm{n}(\%)$ \\
$<1$ ay & $20(45,5)$ \\
$1-3$ ay & $6(13,6)$ \\
3ay-12ay & $7(15,9)$ \\
$1-5$ yaş & $6(13,6)$ \\
$6-10$ yaş & $3(6,8)$ \\
$>10$ yaş & $2(4,5)$ \\
Etkilelen böbrek & $\mathrm{n}(\%)$ \\
Sağ & $11(25)$ \\
Sol & $32(72.7)$ \\
Bilateral & $1(2.3)$ \\
Operayon & $\mathrm{n}(\%)$ \\
Evet & $19(43.2)$ \\
Hayır & $25(56.8)$ \\
\hline
\end{tabular}

Hastaların 18'inde (\% 41) UPD'e eşlik eden böbrek anomalisi mevcuttu. $\mathrm{Bu}$ ek anomalilerden VUR (\%27) en s1k eşlik eden anomali olarak saptandi. En sik başvuru nedeni \% 77.3 oranında antenatal hidronefrozdu. Diğer başvuru nedenleri IYYE, karın/yan ağrısı, işeme bozukluğu ve tesadüfen saptanan hidronefroz şeklindeydi.

Piyeloplasti yapılan ve yapılmayan hastaların SFU, UTD ve ÖNEN evrelemelerine göre hidronefroz şiddetleri kıyaslandı. Cerrahi yapılan hastalar arasinda SFU evre 1, 2 ve 3, Önen evre 1 ve 2 , UTD evre 1 ve 2 sınıflamasına dahil olan hiç hasta yoktu. Cerrahi uygulanan grupta, cerrahi yapılmayanlara kıyasla her üç evreleme içinde istatiksel olarak anlamlı düzeyde şiddetli hidronefroz bulgusu olduğu görüldü $(\mathrm{p}<0.05)$ (tablo 2)

Piyeloplasti uygulanan hastaların ilk başvuru USG bulguları ile 1. yıl USG bulguları değerlendirildiğinde parankimde incelme, pelvis AP çap büyüklüğü bulgularında düzelme olduğu saptand1, ancak bu bulgu istatiksel olarak anlamlı değildi. Piyeloplasti yapılmayan hastalar arasinda 3 hastanın USG bulgularının kötüleştiği görüldü. Veriler tekrar incelendiğinde bu üç hastanın operasyonu kabul etmeyen ailelerin çocukları olduğu saptandı. Diğer hastaların USG bulgularında kötüleşme yoktu. Son kontrol USG bulguları ilk USG ye göre daha iyiydi ya da bulgularda değişme olmamıştı, bu bulgular da istatiksel olarak anlamlı değildi. Cerrahi uygulanan grupta 1, uygulanmayan grupta 10 hastanın son kontrol USG çekimleri yoktu. (Tablo 3).

Başvuruda çekilen MAG3 bulgularına göre cerrahi uygulanan grupta uygulanmayan gruba göre istatiksel olarak anlaml tam ekskresyon yokluğu oranı daha yüksekti $(\mathrm{p}<0.05)$ (tablo 4). Cerrahi uygulanan 3 hastada bașvuruda şiddetli hidronefroz bulguları olmasina rağmen MAG3 sintigrafisi değerlendirmesinde parsiyel ekskresyon vardı. $\mathrm{Bu} 3$ hastanın verileri tekrar incelendi. Parsiyel ekskresyon saptanan hastalara izlem sonras1 bulgularında bozulma olduğu için cerrahi yapıldığ grupta ise 7 hastanın başvuru MAG3 değerlendirmesinde ekskresyonu yoktu. MAG-3 sintigrafisi ile değerlendirilen diferansiyel renal fonksiyonlarda (DRF) her iki grup arasında anlamlı fark yoktu. Cerrahi yapılan gruptaki 13 hastanın DRF'si \% 40' in üzerindeydi ( Tablo 4). Başvuruda ortalama T1/2 zaman1 cerrahi yapilanlarda $\mathrm{T} 1 / 2$ $27.6 \pm 19.6$, cerrahi yap1lmayanlarda $27.9 \pm 24$ olarak saptand. Piyelopilasti yapilan ve yapılmayan hastaların, ilk başvuru ve izlemde birinci y1lda çekilen MAG-3 sintigrafisi bulguları arasında belirgin değişiklik yoktu (Tablo 3). 
Tablo 2. Piyeloplasti uygulanan ve uygulanmayan hastaların ultrasanografi bulgularının evrelemelere göre değerlendirilmesi

\begin{tabular}{clll}
\hline & Piyeloplasti + & Piyeloplasti - & P \\
\hline SFU n (\%) & & & \\
evre 1 & 0 & $1(4)$ & \\
evre 2 & 0 & $3(12)$ & \\
evre 3 & 0 & $14(56)$ & 0.00 \\
evre 4 & $19(100)$ & $7(28)$ & \\
Önen n (\%) & & $3(12)$ & \\
evre 1 & 0 & $14(56)$ & \\
evre 2 & 0 & $8(32)$ & \\
evre 3 & $17(89)$ & 0 & \\
evre 4 & $2(10.5)$ & $3(12)$ & \\
UTD n (\%) & & $14(56)$ & 0.00 \\
evre 1 & 0 & $8(32)$ & \\
evre 2 & 0 & $19(100)$ & \\
evre 3 &
\end{tabular}

SFU; Society of Fetal Urology, UTD; urinary tract dilation

Tablo 3 Piyeloplasti uygulanan ve uygulanmayan hastaların başvuru ve takipte çekilen ultrasanografi ve MAG3 sintigrafi bulgularının değerlendirilmesi

\begin{tabular}{|c|c|c|c|c|c|c|c|c|}
\hline & cerrahi + & & & & cerrahi - & & & \\
\hline & $\begin{array}{l}\text { Başvuru } \\
\mathrm{n}(\%)\end{array}$ & $\begin{array}{l}\text { 1.y1l } \\
\text { n (\%) }\end{array}$ & $\begin{array}{l}\text { Son } \\
\text { kontrol } \\
\mathrm{n}(\%)\end{array}$ & $\mathrm{p}$ & $\begin{array}{c}\text { Başvuru } \\
\mathrm{n}(\%)\end{array}$ & $\begin{array}{l}\text { 1.y1l } \\
\text { n (\%) }\end{array}$ & $\begin{array}{l}\text { son kontrol } \\
\mathrm{n}(\%)\end{array}$ & $\mathrm{p}$ \\
\hline $\begin{array}{l}\text { USG Parankim } \\
\text { incelme var } \\
\text { incelme yok } \\
\text { Toplam }\end{array}$ & $\begin{array}{l}9(47.4) \\
10(52.6) \\
19(100)\end{array}$ & $\begin{array}{l}14(73.7) \\
5(26.3) \\
19(100)\end{array}$ & $\begin{array}{l}8(44.4) \\
10(55.6) \\
18(100)\end{array}$ & 0.13 & $\begin{array}{l}6(24) \\
19(76) \\
25(100)\end{array}$ & $\begin{array}{l}6(\% 24) \\
19(76) \\
25(100)\end{array}$ & $\begin{array}{l}8(53) \\
7(46) \\
15(100)\end{array}$ & 0.48 \\
\hline $\begin{array}{l}\text { USG pelvis ÖA çap } \\
<14 \mathrm{~mm} \\
15-19 \mathrm{~mm} \\
20-24 \mathrm{~mm} \\
>25 \mathrm{~mm} \\
\text { Toplam }\end{array}$ & $\begin{array}{l}1(5.3) \\
6(31.6) \\
2(10.5) \\
10(52.6) \\
19(100)\end{array}$ & $\begin{array}{l}4(21.1) \\
5(26.3) \\
4(21.1) \\
6(31.6) \\
19(100)\end{array}$ & $\begin{array}{l}7(39) \\
6(28.6) \\
2(11.1) \\
3(16.7) \\
18(100)\end{array}$ & 0.19 & $\begin{array}{l}13(52) \\
6(24) \\
6(24) \\
0 \\
25(100)\end{array}$ & $\begin{array}{l}15(60) \\
3(12) \\
6(24) \\
1(4) \\
25(100)\end{array}$ & $\begin{array}{l}5(33.3) \\
3(20.0) \\
5(33.3) \\
2(13.4) \\
15(100)\end{array}$ & 0.33 \\
\hline $\begin{array}{l}\text { MAG3 } \\
\text { Ekskresyon yok } \\
\text { Ekskresyon } \\
\text { parsiyel } \\
\text { Toplam }\end{array}$ & $\begin{array}{l}16(84.2) \\
3(15.8) \\
19(100)\end{array}$ & $\begin{array}{l}11(61) \\
7(38) \\
18(100)\end{array}$ & & 0.42 & $\begin{array}{l}7(28.0) \\
18(72) \\
25(100)\end{array}$ & $\begin{array}{l}6(25) \\
18(75) \\
24(100)\end{array}$ & & 0.93 \\
\hline $\begin{array}{l}\text { MAG3 DRF } \\
<40 \\
>40 \\
\text { Toplam }\end{array}$ & $\begin{array}{l}6(31,9) \\
13(68.4) \\
19(100)\end{array}$ & $\begin{array}{l}8(44.4) \\
10(55.6) \\
19(100)\end{array}$ & & 0.42 & $\begin{array}{l}6(24) \\
19(76) \\
25(100)\end{array}$ & $\begin{array}{l}6(25) \\
18(75) \\
24(100)\end{array}$ & & 0.93 \\
\hline
\end{tabular}

Tablo 4. Hastaların ilk başvuru MAG3 bulguları opere olan ve olmayanlara göre değerlendirmesi

\begin{tabular}{llll}
\hline & cerrahi + & cerrahi - & $\mathrm{p}$ \\
\hline Ekskresyon yok & $16(84.2)$ & $7(28.0)$ & \\
Ekskresyon parsiyel & $3(15.8)$ & $18(72)$ & 0.00 \\
DRF & & & \\
$<40$ & $6(31,9)$ & $6(24)$ & \\
$>40$ & $13(68.4)$ & $19(76)$ & 0.11 \\
\hline \multicolumn{2}{c}{ DRF; diferansiyel renal fonksiyon } & &
\end{tabular}

\section{Tartışma}

Günümüzde çocuklarda UPD darlık derecelendirme yöntemleri ve algoritmler yönetiminde hangi hastalara cerrahi girişim geliştirilmiş olmakla birlikte hiçbirisi altın yapılacağı, hangi hastaları konservatif standart olarak kabul görmemiştir $(1,5,6,7)$. yaklaşım ile takip edileceği tartışmalıdır. UPD UPD yönetiminde merkezimizin deneyimini darlık yönetimine yönelik bir çok değerlendirdiğimiz bu çalışmada, hem cerrahi 
hemde konservatif yaklaşım ile izlenen hastaların USG ve MAG3 bulgularının stabil kaldığı veya iyileştiği saptanmıştır.

Prenatal USG'nin yaygınlaşması ile antenatal hidronefroz tanısı artmış bu da asemptomatik UPD darlık tanı sıklığını arttırmıştır $(3,4)$. UPD erkek çocuklarda ve sol böbrekte daha sık görülür (1). Çalışmaya dahil edilen UPD olgularının da en sık başvuru nedeni antenatal hidronefrozdur. Olguların \%70.5'i erkek ve $\% 72.7$ 'inde sol böbrek etkilenmiştir. Diğer konjenital üriner sistem anomalileri, UPD vakalarının \% 50' ine eşlik edebilir. $\mathrm{Bu}$ anomaliler içinde VUR ve multikistik displastik böbrek en s1k bildirilenlerdir. Ülkemizde Eskişehir'de yapılan çalışmada UPD darlık vakalarına eşlik eden anomali oranı \%20.9 olarak saptanmış, bu vakaların yarısının multikistik displastik böbrek en sik anomali olarak bildirilmiştir (10). Çalışmamızda \% 40.7 oranında eşlik eden üriner sistem anomalisi vard. VUR olgular içinde en sik saptanan ek üriner sistem anomalisi olarak bulundu.

Güncel olarak UPD hastalarının tanısında ve izleminde üriner sistem USG ve dinamik böbrek sintigrafileri kullanılmaktadır. USG' de normal mesane ve üreterler ile birlikte hidronefroz saptanması UPD tanısını düşündürür ancak USG ile böbrek fonksiyonlarını değerlendirilemez. Dinamik sintigrafiler ile böbreğin ekskresyon fonksiyonu ve DRF değerlendirilerek UPD tanis1 konur. $\mathrm{Bu}$ hastalarda UPD olmasina rağmen hastalar arasında hidronefrozun derecesi değişken olduğu gibi hastalığın doğal seyri de değişkendir. $\mathrm{Bu}$ tetkikler hidronefrozun şiddeti ve böbrek fonksiyonu hakkında fikir vermekle birlikte hangi hastanın cerrahiden fayda göreceğini belirleme konusunda güvenilir değildir (1113).

Braga ve ark (4) prenatal hidronefrozu olan 401 bebekten oluşan bir kohortta SFU ve UTD evrelerini kıyaslamışlardır. Bu kohortta hem SFU hem de UTD derecesine göre bir y1ll1k takipte $\% 50$ oranında hidronefrozda düzelme olduğunu göstermişlerdir. Arena ve ark. (14) ortalama 14 yıllık takipte sintigrafide kötü ekskresyon bulgusu olsa bile hem SFU hemde UTD evrelerine göre hafif düzeyde hidronefrozu olan olgularda, UPD rezolüsyon oranın yüksek olduğu ve bu hastaların güvenle konservatif yaklaşımda takip edilebileceğini bildirmişlerdir. Aynı çalışmada şiddetli hidronefroz olan olgularda UPD rezolusyonun düşük olduğu bildirilmiştir. Sunulan çalışmaya dahil edilen olguların geriye dönük USG bulguları literatürde önerilen SFU, Önen ve UTD evrelemelerine göre yeniden değerlendirildi. Cerrahi uygulanan hastaların hepside bu evrelere göre şiddetli hidronefroz bulgularına sahipti. Cerrahi uygulanmayan hastaların ise SFU'a göre \% 28 (7 hasta), Önen' e göre \%32 (8 hasta), UTD'te göre \%32 (8 hasta) şiddetli hidronefroz bulguları mevcuttu. $\mathrm{Bu}$ hastaların verileri tek tek incelendi. Hepsinin MAG3 sintigrafisine göre DRF'nin \%45'in üzerinde olduğu için takibe alındığı izlemde hidronefroz bulgularında gerileme olduğu görüldü.

UPD olgularında MAG3 çekimi ve yorumlanması önemlidir. Sintigrafi filmini çeken nükleer tıp uzmanı ve teknisyenlerin deneyimi önemlidir. Zira hastanın işlem öncesi hidrasyon durumu ve mesanenin dolu olması böbreğin drenaj fonksiyonunun $\left(\mathrm{T}^{1} / 2\right)$ değerlendirilmesinde hatalı sonuçlara neden olabilir (15). Aynı zamanda UPD vakalarının bir kısmında etkilenen böbrekte DRF \% 55 ve üzerinde çıkabilmekte bu durum literatürde supranormal olarak isimlendirilmektedir. Obstruksiyonun önemli bir belirteci olan DRF'nin bu sonucunun bir hesaplama hatas1 olabileceği gibi hasarlı böbrekte hiperfiltrasyonun bir sonucu olabileceği de ileri sürülmektedir (16,17). Çalışmamızda opere edilen 13 hastanın başvuruda ki DRF'nin \% 40'1n üzerinde olduğu saptandı. $\mathrm{Bu}$ hastaların verileri tekrar incelendiğinde, hastaların izleme alındığı, izlemde bazılarının hidronefroz bulgularında artış olduğu, bazılarında ise DRF'da \%10 dan fazla düşme olduğu için opere edildiği görüldü.

Literatürde cerrahi endikasyonu için tam bir standart olmamakla birlikte; $\mathrm{DRF}<\% 40$ olmas1 ya da takipte DRF'de \%10'dan fazla düşüş, SFU'a göre evre 4 hidronefroz, AP çap $>40 \mathrm{~mm}$, diğer böbrekte MKDB, VUR gibi anomalilerin olması, hastada yan ağrıs1, hipertansiyon ve tekrarlayan IYE gibi semptomların olması cerrahi kararı için önerilen parametrelerdir $(1,5,18)$. 
Vemulakonda V.M. ve ark. (18) 197 UPD hastasını inceledikleri çalışmada cerrahiye karar vermede kaliksiyel dilatasyonla birlikte hidronefroz varlığının ön planda kullanıldığını, DRF' nin cerrahiye karar vermede kullanmadığını bilmişlerdir. Aynı çalışmada DRF'yi cerrahiye karar vermede kullanmaktan ziyade bazal renal fonksiyonu değerlendirmek için kullanılabileceği bildirmişlerdir. Kliniğimizde UPD tanısı ile izlenen hastalar nefro-üroloji konseyi yapılarak değerlendirilmektedir. Olgularda ilk değerlendirmede USG'de pelvis AP çap düzeyi, parankim incelmesi varlığı, MAG3 sintigrafide DRF fonksiyonda azalma $(<\% 40)$ ve tam obstrüksiyon varlığ hastalarda ise hidronefroz şiddetinde artma ve/veya DRF fonksiyonda $\% 10$ ve daha fazla düşme olması dikkate alınarak cerrahi kararı verilmektedir. Konservatif olarak izlenen olgularda olgunun ciddiyetine göre 3-6 ayda bir USG ve yine olguda gereklilik halinde 6 aydan erken olmamak üzere genelikle 1 yil sonra MAG3 sintigrafi tekrar1 yapılmas1 şeklindedir. Ancak konservatif yaklaşım ile izlenen hasta grubunda bazı çocukların ailelerinin kontrolleri aksattığ veya radyasyon almasını istemediği için kontrol MAG3 tetkiki

\section{KAYNAKLAR}

1. Krajewski W, Wojciechowska J, Dembowski J et al. Hydronephrosis in the course of ureteropelvic junction obstruction: An underestimated problem? Current opinions on the pathogenesis, diagnosis and treatment. Adv Clin Exp Med. 2017;26:85764.

2. Szydelko T, Tuchendler T, Litarski A, et al. Laparoscopic Anderson-Hynes procedure as a treatment of ureteropelvic junction obstruction caused by fibroepithelial polyp. Wideochir Inne Tech Malo Inwazyjne. 2013;8:361-63.

3. Woodward M, Frank D. Postnatal management of antenatal hydronephrosis. BJU Int. 2002;89:14956

4. Braga LH, Ruzhynsky V, Pemberton $\mathrm{J}$ et al. Evaluating practice patterns in postnatal management of antenatal hydronephrosis: a national survey of Canadian pediatric urologists and nephrologists. Urology. 2014;83:909-14.

5. Weitz M, Schmidt M, Laube G. Primary nonsurgical management of unilateral ureteropelvic junction obstruction in children: a systematic review. Pediatr Nephrol. 2017;32:2203-13.

6. Onen A. Grading of Hydronephrosis: An Ongoing Challenge. Front Pediatr. 2020; 27;8:458.

7. Nguyen HT, Benson CB, Bromley B et al. Multidisciplinary consensus on the classification çektirmediği görüldü. $\mathrm{Bu}$ durum konservatif yaklaşım ile izlenmeye karar verilen çocukların ailelerinin de sosyokültürel düzeylerinin izlem kararı verirken dikkate alınması gerektiğini bize düşündürdü.

$\mathrm{Bu}$ çalışmanın retrospektif olması ve vaka sayının az olması çalışmanın en önemli kısıtlılığıdır. Görüntüleme yöntemlerinden MAG3 sintigrafi çekimlerinin tamamının hastanemiz bünyesinde yapılmış olmasına karşın USG çekimlerinin farklı merkezlerde yapıımış olması bu çalışmanın diğer bir kısitlılığıdır. UPD cerrahisi sonrası renal fonksiyonlarda düzelme 5 yılı bulabilmektedir $(19,20)$. Özellikle cerrahi yapılan hasta grubunda takip süresinin kısa olması düzelme oranının daha düşük saptanmasına neden olmuş olabilir.

Sonuç olarak UPD olgularının yönetimi için altın standart yöntem yoktur. $\mathrm{Bu}$ hasta grubunda USG ve MAG3 sonuçlarının birlikte yorumlanması, çocuk nefroloji ve çocuk üroloji doktorlarının merkezlerinde ortak bir yol haritası izlemeleri önemlidir. of prenatal and postnatal urinary tract dilation (UTD classification system). $J$ Pediatr Urol. 2014;10:982-98

8. Williams B, Tareen B, Resnick MI. Pathophysiology and treatment of ureteropelvic junction obstruction. Curr Urol Rep. 2007;8:11117.

9. Ingraham SE, McHugh KM. Current perspectives on congenital obstructive nephropathy. Pediatr Nephrol. 2011;26:1453-61.

10. Çetin N, Tokar B. Çocuklarda Üreteropelvik Bileşke Darlığı: Tek Merkez Deneyimi. Firat Tip Dergisi. 2017; 22: 77-80.

11. Gopal M, Peycelon M, Caldamone A, et al. Management of ureteropelvic junction obstruction in children-a roundtable discussion. $J$ Pediatr Urol. 2019;15:322-29.

12. Abadir N, Schmidt M, Laube GF et al. Imaging in children with unilateral ureteropelvic junction obstruction: time to reduce investigations? Eur $J$ Pediatr. 2017;176:1173-79.

13. Kohno M, Ogawa T, Kojima $\mathrm{Y}$ et al. Pediatric congenital hydronephrosis (ureteropelvic junction obstruction): Medical management guide. Int $J$ Urol. 2020;27:369-76.

14. Arena S, Chimenz R, Antonelli E et al. A longterm follow-up in conservative management of 
unilateral ureteropelvic junction obstruction with poor drainage and good renal function. Eur $J$ Pediatr. 2018;177:1761-5.

15. Bayne CE, Majd M, Rushton HG. Diuresis renography in the evaluation and management of pediatric hydronephrosis: What have we learned? J Pediatr Urol. 2019;15:128-37.

16. Oh SJ, Moon DH, Kang W et al. Supranormal differential renal function is real but may be pathological: assessment by $99 \mathrm{~m}$ technetium mercaptoacetyltriglycine renal scan of congenital unilateral hydronephrosis. J Urol. 2001;165:23004.

17. Moon DH, Park YS, Jun N-L et al. Value of supranormal function and renogram patterns on $99 \mathrm{mTc}$-mercaptoacetyltriglycine scintigraphy in relation to the extent of hydronephrosis for predicting ureteropelvic junction obstruction in the newborn. J Nucl Med. 2003;44:725-31.

18. Vemulakonda VM, Sevick C, Juarez-Colunga E et al. Treatment of infants with ureteropelvic junction obstruction: findings from the PURSUIT network. Int Urol Nephrol. 2021;53:1485-95.

19. Chertin B, Pollack A, Koulikov D et al. Does renal function remain stable after puberty in children with prenatal hydronephrosis and improved renal function after pyeloplasty? $J$ Urol. 2009; 182:1845-8.

20. Chandrasekharam VVS, Babu R, Arlikar J et al. Functional outcomes of pediatric laparoscopic pyeloplasty: post-operative functional recovery is superior in infants compared to older children. Pediatr Surg Int. 2021;37:1135-39. 